\title{
Wind energy-hydrogen storage hybrid power generation
}

\author{
Wen-Jei Yang*, ${ }^{\dagger}$ and Orhan Aydin ${ }^{\ddagger}$ \\ Department of Mechanical Engineering and Applied Mechanics, University of Michigan, Ann Arbor, MI 48109-2125,U.S.A.
}

\begin{abstract}
SUMMARY
In this theoretical investigation, a hybrid power generation system utilizing wind energy and hydrogen storage is presented. Firstly, the available wind energy is determined, which is followed by evaluating the efficiency of the wind energy conversion system. A revised model of windmill is proposed from which wind power density and electric power output are determined. When the load demand is less than the output of the generation, the excess electric power is relayed to the electrolytic cell where it is used to electrolyze the de-ionized water. Hydrogen thus produced can be stored as hydrogen compressed gas or liquid. Once the hydrogen is stored in an appropriate high-pressure vessel, it can be used in a combustion engine, fuel cell, or burned in a water-cooled burner to produce a very high-quality steam for space heating, or to drive a turbine to generate electric power. It can also be combined with organic materials to produce synthetic fuels. The conclusion is that the system produces no harmful waste and depletes no resources. Note that this system also works well with a solar collector instead of a windmill. Copyright (C) 2001 John Wiley \& Sons, Ltd.
\end{abstract}

KEY WORDS: hybrid power generation; wind energy; hydrogen storage; renewable energy; no pollution

\section{INTRODUCTION}

Wind power is a very efficient source of energy in areas that are invariably windy. Typical high wind regimes occur in areas of low-priority land use and collection area is perpendicular to the ground surface and occupies only a small fraction of the area from which the energy is captured. Wind power has many advantages including the facts that it produces virtually no pollution of air, water or soil; it is renewable (non-depletable). There is enough potential wind energy in the U.S. to power the entire country. Yet, wind creates 1 per cent of the states' production. The total installed wind capacity of U.S. is nearly $1900 \mathrm{MW}$ with the approximately $900 \mathrm{MW}$ planned new

\footnotetext{
* Correspondence to: Wen-Jei Yang, Department of Mechanical Engineering and Applied Mechanics, University of Michigan, Ann Arbor, Michigan 48109-2125, U.S.A.

† E-mail: wjyang@engin.umich.edu

${ }^{\ddagger}$ Visiting scholar on leave from the Department of Mechanical Engineering, Karadeniz Technical University, 61080 Trabzon, Turkey.
}

Contract/grant sponsor: TUBITAK

Contract/grant sponsor: NATO 
generating capacity. While the wind energy is certainly a strong renewable energy source, it is also an erratic one. The wind is gusty from moment to moment, and there is a large seasonal variation in winds. If the wind power is to supply a significant portion of the demand, energy storage is needed. In the past, the poor efficiencies of energy storage systems prevented wind from becoming an economically feasible source of energy. However, improved technology has put the conversion of wind energy to electrical energy within reach. Wind farm experiments have shown that the use of electrical energy derived from wind power appears to most feasible if wind energy can be supplemented by other forms of energy in a hybrid system. Ashenayi and Ramakumar (1990) presented an approach to design an integrated renewable energy systems (IRES) based on the loss of power-supply probability (LPSP) as the key system parameter and minimization of the initial capital investment. Also, a computer program named IRES was developed for use as a design tool. A knowledge-based design approach that minimized the total capital cost at a pre-selected reliability level was presented by Ramakumar et al. (1992). The reliabilty level was quantified by the LPSP. The procedure included some resource-need matching based on economics, the quality of energy needed, and the characteristics of the resource. A detailed example was also presented and discussed to illustrate the usefulness of the design approach. In another article, Ramakumar et al. (1995) discussed some typical design scenarios and tile formulation of designs using the knowledge-based design tool IRES-KB with the aid of KAPPA(R)-PC development tools. A remote village with no electrical grid connection was chosen for the study since renewables were most likely to make their greatest impact in such locations. Yokoyama et al. $(1994,1997)$ presented a deterministic approach (1994) and a probabilistic approach (1997) to optimal unit sizing for hybrid power generation systems utilizing photovoltaic and wind energy. Device capabilities and electric contract demand were determined so as to minimize the annual total cost and annual energy consumption from the viewpoints of economy and energy saving or reduction in $\mathrm{NO}_{x}$ and $\mathrm{CO}_{2}$ emission, respectively. This optimization problem was considered as a multiobjective one, and a discrete set of Pareto optimal solutions was derived numerically by using the weighting method. Borowy and Salameh $(1994,1996)$ developed a methodology for calculation of the optimum size of a PV array for a stand-alone hybrid wind/PV system. Barley and Winn (1996) compared dispatch strategies using (1) an analysis of cost trade-offs, (2) a simple, quasi-steadystate time-series model, and finally (3) HYBRID-2, a more sophisticated stochastic time-series model. An idealized predictive dispatch strategy, based on assumed perfect knowledge of future load and wind conditions, was developed and used as a benchmark in evaluating simple, non-predictive strategies. The results illustrated the nature of the optimal strategy and indicated that one of two simple diesel dispatch strategies-either load-following or full power for a minimum run time - could be in conjunction with the frugal use stored energy (the frugal discharge strategy), be virtually as cost effective as the ideal predictive strategy. The optimal choice of these two simple charging strategies was correlated to three dimensionless parameters, yielding a generalized dispatch design chart for an important class of systems. Markvart (1996) described a procedure determining the sizes of the PV array and wind turbine in a PV/wind energy hybrid system. Using the measured values of solar and wind energy at a given location, the method employed a simple graphical construction to determine the optimum configuration of the two generators that satisfied the energy demand of the user throughout the year. The application of a hybrid wind/photovoltaic (PV) power generating systems for utilization as a stand-alone or a network connected system was investigated by Kellogg et al. (1994). The optimum combination of wind and PV generation coupled with battery storage for a stand-alone system was obtained for a hypothetical site in Montana. Kellogg et al. (1997) also investigated the application of wind, 
photovoltaic (PV), and hybrid wind/PV poer generating systems for utilization as stand-alone systems using a simple numerical algorithm. A general method was developed to jointly determine the sizing and operation control of hybrid-PV systems by Seelin-Hochmuth (1997). With this method the interdependency of hybrid operation strategies and system sizing could be incorporated. Operation strategies were selected by searching through possible settings for the system operation control, considering the nonlinear characteristics of some components. The operation control and sizing selection method was based on genetic optimization techniques. Modelling of hybrid power systems including the optimization of the dispatch strategy was presented by Ashari and Nayar (1999). A computer program for a typical dispatch strategy was developed to predict the long-term energy performance and the lifecycle cost of the system. Peterson et al. (1999) reported on the operational experience acquired with a photovoltaic (PV) hybrid system installed as a line extension alternative at a residence located in northern New York State. The paper featured a detailed analysis of the energy flows through the system and quantified all losses caused by battery storage round-trip, rectifier and inverter conversions, and non-optimum operation of the generator and of the PV array. The paper also analysed the evolution of end-use electricity consumption since the installation of the PV hybrid system. A methodology was developed Muselli et al. (1999) for calculating the correct size of a photovoltaic (PV)-hybrid system and for optimizing its management. The power for the hybrid system came from PV panels and an engine-generator - that was, a gasoline or diesel engine driving an electrical generator. Bonanno et al. (1999) developed a software package to evaluate the transient behaviours of hybrid systems during planning stage.

There are several storage options (Andrews, 1976; Ramakumar, 1976; Swet, 1981) but hydrogen storage shows the most promise. Not only is hydrogen a 'clean energy source', but also it possesses high applicability. Hydrogen can be used as a fuel by itself or can be combined with organic materials to produce synthetic fuels (methane, methanol). It can be used in a fuel cell to generate electricity or can be burned with oxygen in water-cooled burner to produce high-quality steam which in turn can drive a turbine-generator to generate electricity. Hydrogen production and storage represent the only readily available technology that can be reliably store renewable energy to supply the electricity and fuel customers of the 21 st century. Wind and solar power can seriously compete with all other sources only when the hourly, daily and seasonal variations can be effectively removed. It is the object of this paper to model a wind energy-hydrogen storage cycle. The model is based on the system in Figure 1, and will cover from the wind input to the storage. The literature pertinent to wind energy and hydrogen storage is available in textbooks, journals and conference proceedings and is thus omitted here in the interest of brevity.

\section{WIND ENERGY SYSTEM}

This section presents (i) available wind energy, (ii) wind energy conversion system (WECS) energy, (iii) windmill model, and (iv) windmill analysis.

\subsection{Available energy}

A wind machine cannot intercept all of the energy theoretically available in the wind. As the wind speed increases, the machine begins to supply power only at the 'cut-in' speed $V_{m}$. At the cut in 


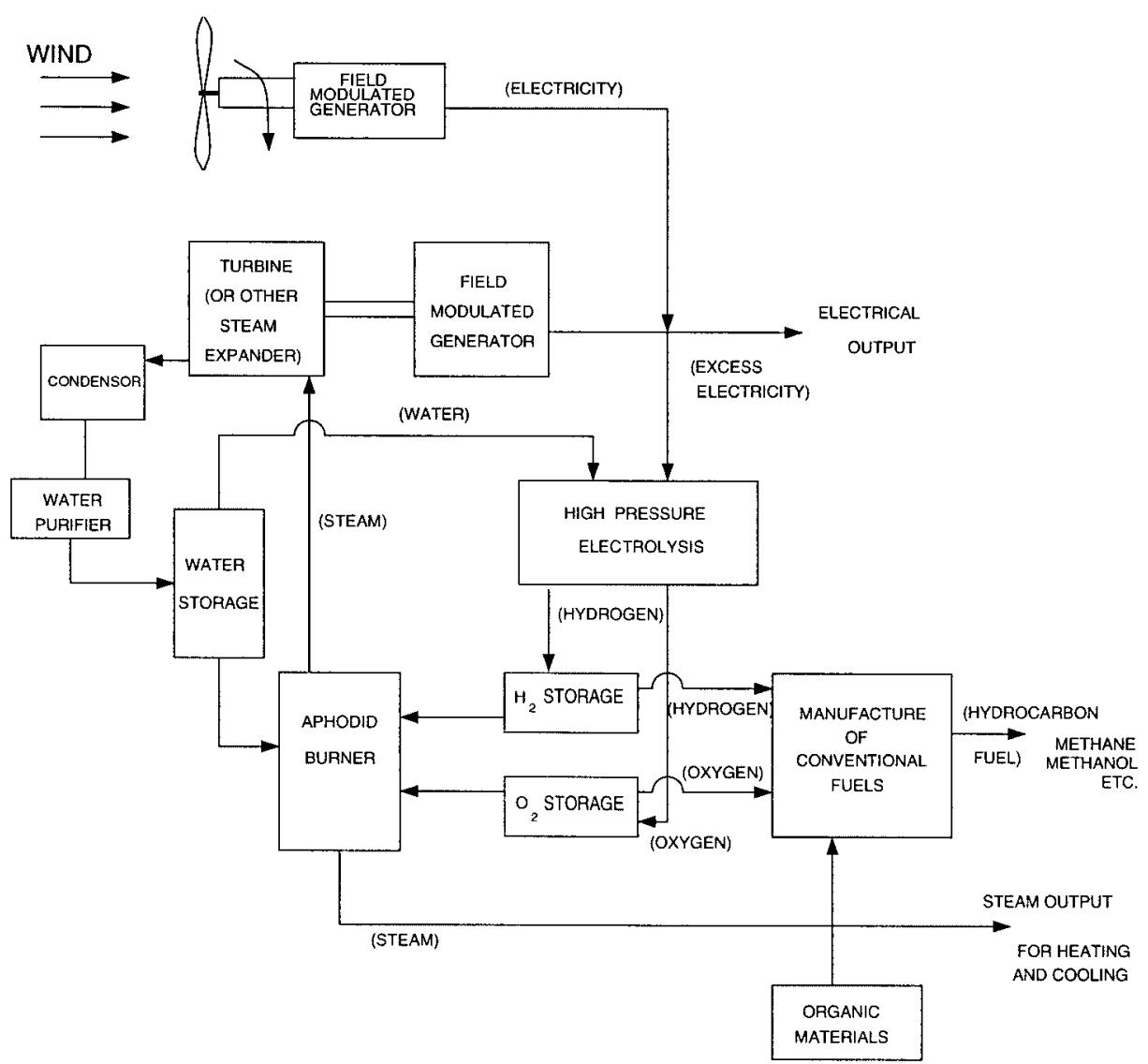

Figure 1. Flow diagram illustrating wind energy-hydrogen storage hybrid power generation system.

speed, the power available on the windmachine shaft equals the power absorbed by the no-load losses of the whole set. As the wind speed increases beyond $V_{m}$, it attains its 'rated wind speed' $V_{n}$ which is the speed at which the machine supplies its rated power (power is kept constant here by a regulating system). If the wind velocity continues to increase, it will eventually reach the value $V_{\mathrm{c}}$ which is called the 'cut-out speed'. At this speed, the machine is stopped for safety reasons and gives no more power. Figure 2(a) shows a plot of wind velocity versus time. The actual available area is obtained by multiplying the cross-hatched area $\left(\mathrm{kWh} \mathrm{m}^{-2}\right)$ with the coefficient of efficiency for the wind turbine.

The ratio of the actual available energy by a given machine and the energy obtained by considering wind speed as a constant equal to the average annual value is expressed as

$$
r_{\mathrm{e}}=\frac{V_{n}^{3}\left(t_{2}-t_{1}\right)+\int_{t_{2}}^{t_{3}} V^{3} \mathrm{~d} t}{\bar{V}^{3}}
$$



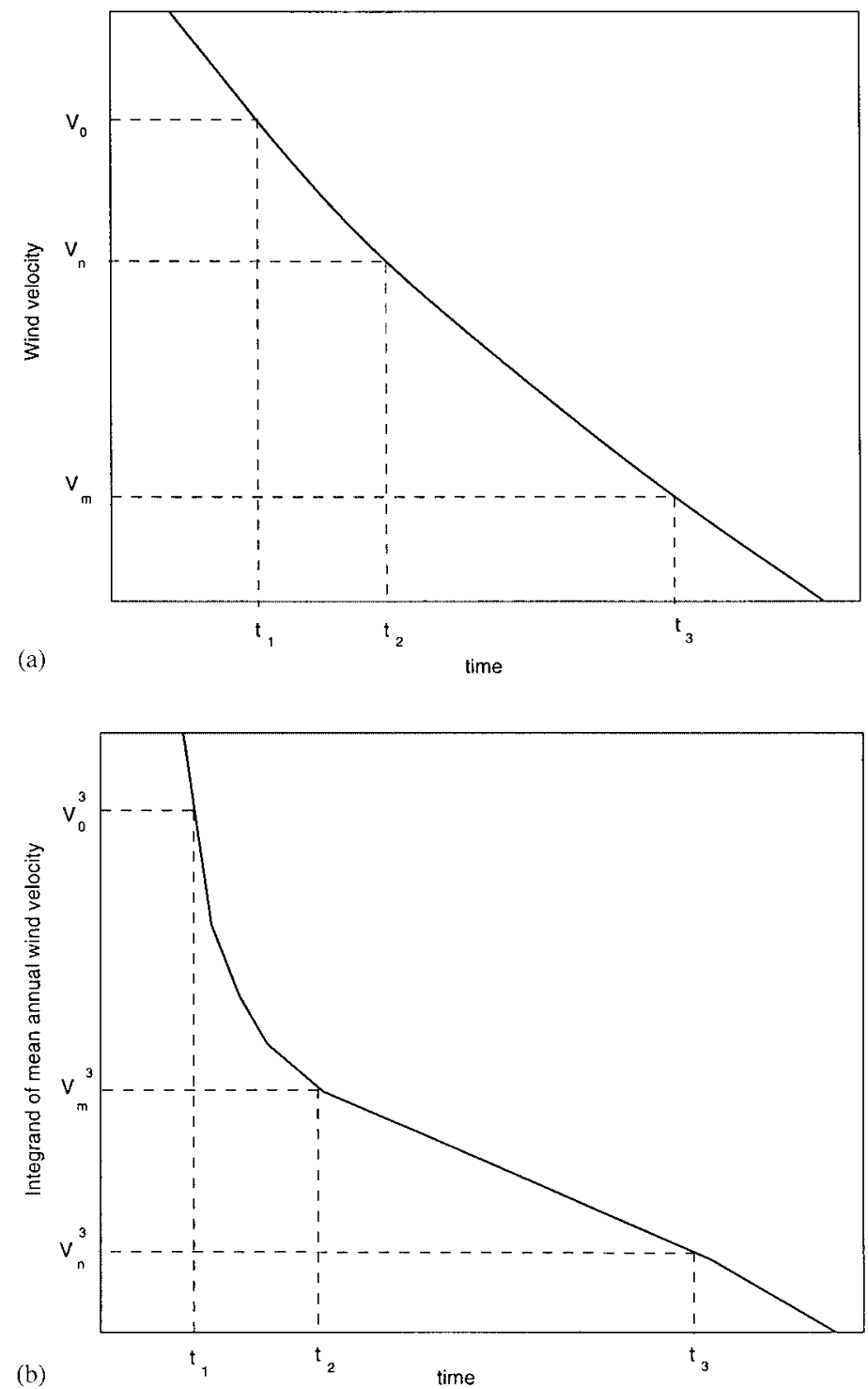

Figure 2. Timewise variation of (a) wind velocity, $V$ and (b) integrand of mean annual wind velocity, $V^{3}$.

Here, $r_{\mathrm{e}}$ denotes the ratio of available energy by machine and available energy from $\bar{V} ; V$, instantaneous wind speed; $\bar{V}$, mean annual speed $=1 / t_{0}^{t} V^{3} \mathrm{~d} t ; t_{1}$, annual time at which the wind speed $(V)$ is greater than the cut out speed $\left(V_{c}\right) ; t_{2}$, annual time during which the speed $(V)$ is greater than the rated speed $\left(V_{n}\right)$; and $t_{3}$, annual time during which the speed $(V)$ is greater than the cut-in speed $\left(V_{m}\right)$.

For the analysis given, the variation of integrand of the annual mean wind velocity is given in Figure 2(b). 


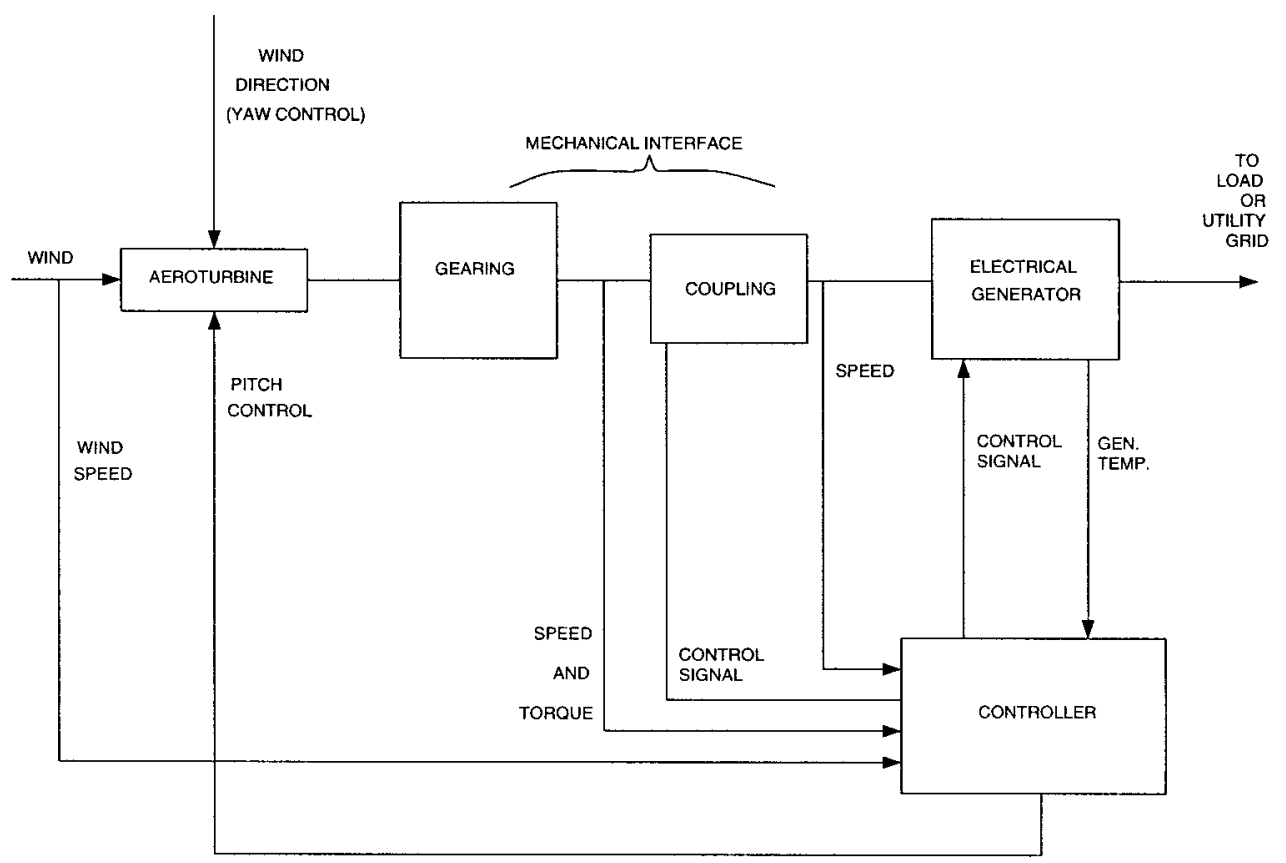

Figure 3. Basic components of wind-electric system.

\subsection{WECS efficiency}

Figure 3 illustrates the basic components of the wind conversion system (WECS). The overall conversion efficiency $\left(\eta_{\text {ov }}\right)$ of a general aerogenerator is defined as

$$
\eta_{\mathrm{ov}}=\frac{\text { Useful output power }}{\text { Wind power input }}=\eta_{\mathrm{a}} \eta_{\mathrm{g}} \eta_{\mathrm{c}} \eta_{\mathrm{ge}}
$$

where the subscripts a, c, g and ge refer to aeroturbine, mechanical coupling, generator, and gearing, respectively.

The overall efficiency is strongly determined by the lowest efficiency converter in the cascade; in this case the aeroturbine efficiency. The other efficiencies can be made quite high. The efficiency of the aeroturbine can be expressed as

$$
\eta_{\mathrm{a}}=\frac{\text { Useful shaft power output }}{\text { Wind power input }}=c_{P}=\text { Power coefficient }
$$

The aeroturbine efficiency has been derived to be

$$
\eta_{\mathrm{a}}=\left(1-k \frac{V_{\mathrm{t}}}{V_{\mathrm{w}}}\right) /\left(1+k \frac{V_{\mathrm{w}}}{V_{\mathrm{t}}}\right)=c_{p}
$$

where $k$ denotes the drag/lift ratio defined as $F_{\mathrm{d}} / F_{1} ; V_{\mathrm{t}}$, wind velocity of blade element in plane of rotation due to blade turning; $V_{\mathrm{w}}$, impinging wind velocity; and $V_{\mathrm{t}} / V_{\mathrm{w}}$ tip speed ratio. 


\subsection{Windmill model}

In the conventional windmill model, the windmill power and torque are given by

$$
\begin{gathered}
P_{\mathrm{w}}=c_{p} P_{i} \\
\tau_{\mathrm{w}}=c_{t} \tau_{i}
\end{gathered}
$$

and the wind power $P_{i}$ and wind torque $\tau_{i}$ are

$$
\begin{gathered}
P_{i}=\rho \cdot A \cdot V_{\mathrm{w}}^{3} / 2 \\
\tau_{i}=\rho \cdot A \cdot R \cdot V_{\mathrm{w}}^{2} / 2
\end{gathered}
$$

Here, $\rho, A$ and $R$ are the air density, sweep area and rotor radius, respectively. Although $P_{\mathrm{w}}$ and $\tau_{w}$ can be determined readily, losses power and torque losses must be added to the relation. Therefore, in the revised windmill model,

$$
\begin{aligned}
P_{i} & =P_{\mathrm{w}}+P_{f} \\
\tau_{i} & =\tau_{\mathrm{w}}+\tau_{f}
\end{aligned}
$$

where $P_{f}$ and $\tau_{f}$ are windmill power and torque losses accounted for by $c_{p}$ and $c_{\tau}$.

The windmill torque loss $\tau_{f}$, is a function of windmill shaft speed $(\mathrm{N})$, a good approximation of this function can be written as

$$
\tau_{f}=f_{0}+f_{1} N+f_{2} N^{2}+f_{3} N^{3}
$$

where $f_{0}, f_{1}, f_{2}, f_{3}$ represent torque loss coefficients. The torque loss coefficients are a function of wind speed and are given by

$$
f_{0}=k_{f_{0}} V_{\mathrm{w}}^{2}, f_{1}=k_{f_{1}} V_{\mathrm{w}}, f_{2}=k_{f_{2}}, f_{3}=k_{f_{3}} / V_{\mathrm{w}}
$$

By combining the system of torque equations:

$$
\tau_{\mathrm{w}}=c_{\tau} \tau_{i} \text { and } \tau_{i}=\tau_{\mathrm{w}}+\tau_{f}
$$

An equation for the torque coefficient can be derived:

$$
c_{\tau}=1-\left(1 / \tau_{i}\right)\left(f_{0}+f_{1} N+f_{2} N^{2}+f_{3} N^{3}\right)
$$

The windmill torque coefficient is related to the tip speed ratio as in Figure 4. $c_{\tau}$ can be approximated by

$$
c_{\tau}=\alpha\left(V_{\tau} / V_{\mathrm{w}}\right)^{3}+\beta\left(V_{\tau} / V_{\mathrm{w}}\right)^{2}+\gamma\left(V_{\tau} / V_{\mathrm{w}}\right)+\sigma
$$

The coefficients $k_{f_{0}}$ and $k_{f_{1}} \ldots$ are obtained by combining $c_{\tau}, f_{0}, f_{1}, f_{2}, f_{3}$ and $\tau_{i}$ to get

$$
\begin{aligned}
& k_{f_{0}}=-(\sigma-1) \rho \cdot A \cdot R / 2 \\
& k_{f_{1}}=-\gamma \rho \cdot A \cdot R^{2} / 2 \\
& k_{f_{2}}=-\beta \cdot \rho \cdot A \cdot R^{3} / 2 \\
& k_{f_{3}}=-\alpha \cdot \rho \cdot A \cdot R^{4} / 2
\end{aligned}
$$

The coefficients $k_{f_{0}}$ and $k_{f_{1}}$ can be obtained from published $c_{\tau}$ and $V_{\tau} / V_{\mathrm{w}}$ characteristics of existing windmills. The results are shown in Figure 5. 


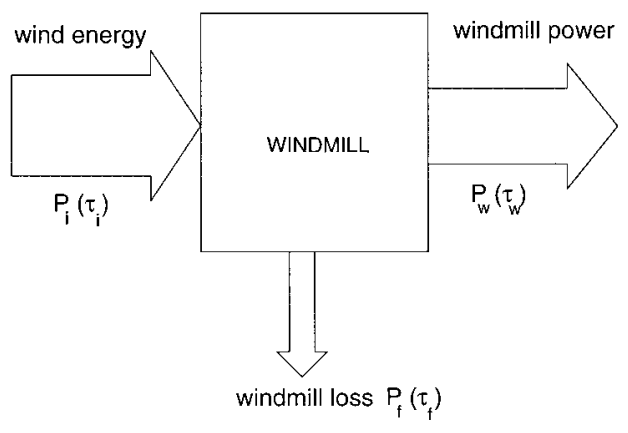

Figure 4. Revised windmill model.

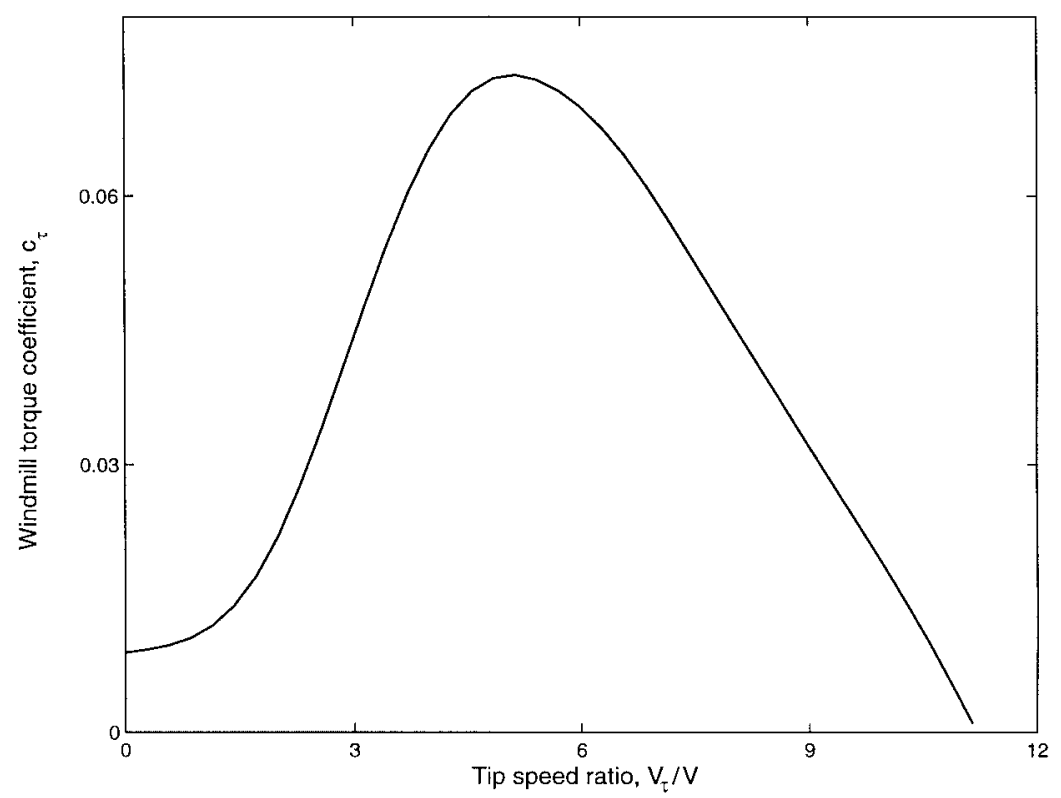

Figure 5. Windmill torque coefficient versus tip-speed ratio.

The equation for the entire power system is

$$
\tau_{i}=\tau_{\mathrm{w}}+\tau_{f}
$$

or

$$
\tau_{i}=\tau_{\mathrm{w}}+f_{0}+f_{1} N+f_{2} N^{2}+f_{3} N^{3}
$$

\subsection{Windmill analysis}

Since the power density in moving air varies directly with wind speed by the relation

$$
P_{i}=c_{p}\left(\frac{1}{2} A \cdot \rho \cdot V_{\mathrm{w}}^{3}\right)
$$



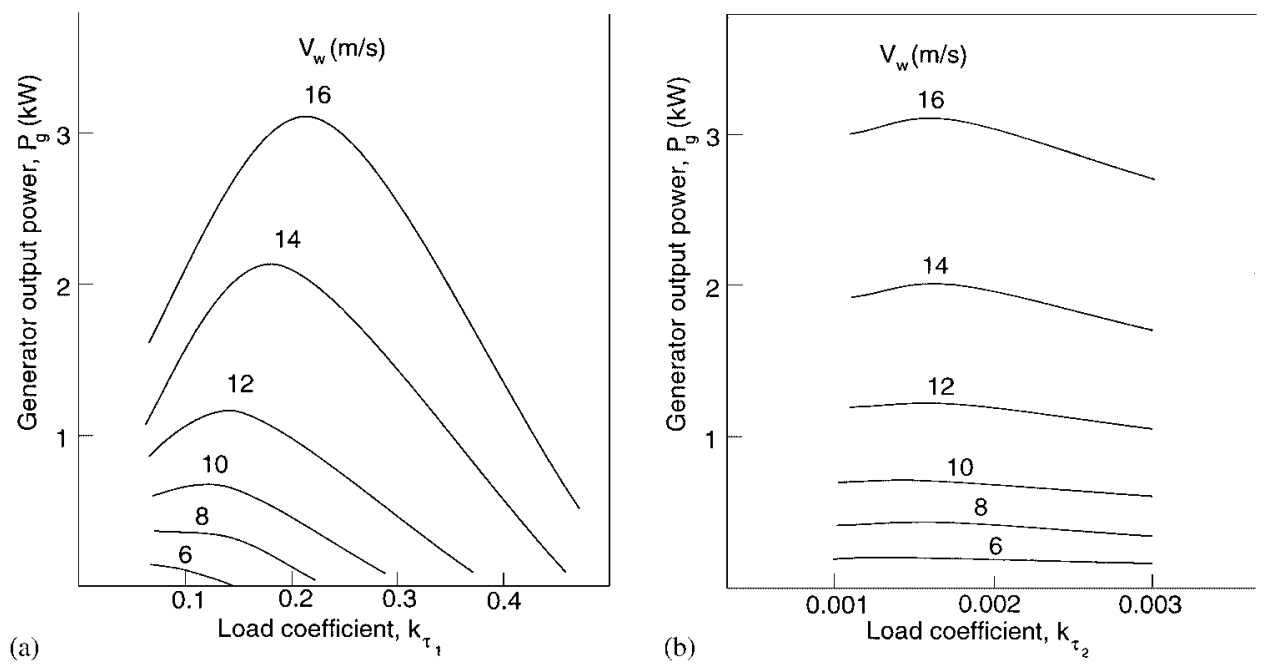

Figure 6. Generator output power versus load coefficients (a) $k_{\tau_{1}}$ (b) $k_{\tau_{2}}$.

it is clear that the characteristics of a windmill power system depend greatly on wind speed and windmill torque coefficient. The windmill torque coefficient depends on windmill type and blade pitch. By using a computer, the torque and power coefficients of a horizontal axis wind turbine can be found as a function of tip-speed ratio.

Using the windmill torque coefficients and power coefficients in the results, the load torque coefficients $k_{\tau_{1}}$ and $k_{\tau_{2}}$ can be related to the generator output power $\left(P_{\mathrm{g}}\right)$ in Figures 6(a) and 6(b), respectively. It is seen that the maximum output power is reached at a particular value of the load torque coefficient and is more sensitive to changes in $k_{\tau_{1}}$ and than in $k_{\tau_{2}}$ at high wind speeds.

\subsection{Windmill system with DC generator}

Since the electrolysis system for the present model system requires a DC electrical input, it is practical to provide the propeller system with a DC generator, therefore eliminating the need for a power regulator.

A typical windmill with DC generator is schematically shown in Figure 7. When the load resistance $R_{1}$ is connected to the DC generator, the generated voltage equation is

$$
E=k_{v}+R_{a} I_{1}+V_{b}+R_{1} I_{1}
$$

The generator output torque $\tau_{\mathrm{g}}$ and power $P_{\mathrm{g}}$ are expressed as

$$
\begin{gathered}
\tau_{\mathrm{g}}=k_{\tau} I_{1}=\frac{k_{v} N-V_{b}}{R_{a}+R_{1}} \\
P_{\mathrm{g}}=R_{1} I_{1}^{2}
\end{gathered}
$$

$\tau_{i}$ is given as

$$
\tau_{i}=\tau_{\mathrm{w}}+\tau_{f}
$$




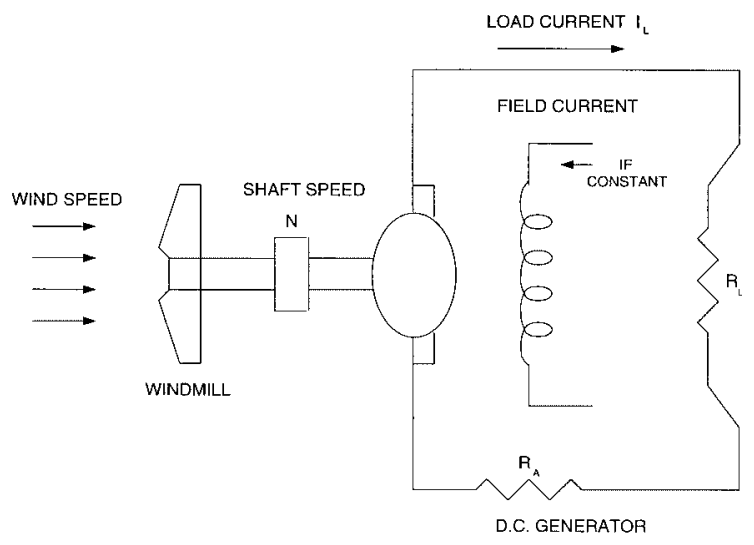

Figure 7. A schematic of windmill with DC generator.

Table I. List of test parameters to determine the performance of shaft speed and generator output power.

\begin{tabular}{ll}
\hline$\rho=1.204\left(\mathrm{~N} \mathrm{~s}^{2} \mathrm{~m}^{-4}\right)$ & Voltage $=24(\mathrm{~V})$ \\
$R=0.95(\mathrm{~m})$ & Current $=15(\mathrm{~A})$ \\
$k_{t_{1}}=0.05-0.5\left(\mathrm{~N} \mathrm{~m} \mathrm{rad}^{-1} \mathrm{~s}^{-1}\right)$ & Speed $=800(\mathrm{rmm})$ \\
$k_{t_{2}}=0.001-0.003\left(\mathrm{~N} \mathrm{~m} \mathrm{rad}^{-2} \mathrm{~s}^{-2}\right)$ & $K_{\tau}=0.432\left(\mathrm{~N} \mathrm{~m} \mathrm{~A}^{-1}\right)$ \\
$\alpha=0$ & $K_{v}=0.432\left(\mathrm{~V} \mathrm{rad}^{-1} \mathrm{~s}^{-1}\right)$ \\
$\beta=-2.13 \times 10^{3}$ & $\tau_{\mathrm{gc}}=0.541(\mathrm{~N} \mathrm{~m})$ \\
$\gamma=0.0246$ & $R_{\mathrm{a}}=0.34(\Omega)$ \\
$\sigma=-7.53 \times 10^{-4}$ & $V_{b}=2.0(\mathrm{~V})$ \\
\hline
\end{tabular}

where

$$
\begin{gathered}
\tau_{\mathrm{w}}=f_{\mathrm{g}} N+\tau_{\mathrm{gc}}+\tau_{\mathrm{g}} \\
\tau_{f}=f_{0}+f_{1} N+f_{2} N^{2}+f_{3} N^{3}
\end{gathered}
$$

Using the generator output torque equation above, an equation for the wind torque can be generated:

$$
\tau_{i}=k_{f_{0}} V_{\mathrm{w}}^{2}+k_{f_{1}} V_{\mathrm{w}} N+k_{f_{2}} N^{2}+\tau_{\mathrm{gc}}+f_{\mathrm{g}} N+k_{\tau} \frac{k_{v} N-V_{b}}{R_{a}+R_{1}}
$$

where $k_{f_{2}} N^{2}$ represents the windmill torque loss.

From the equation above, several observations can be made:

(1) The load torque increases with the shaft speed.

(2) The shaft speed is determined by the wind speed and the load resistance.

(3) The load current and finally the generator power can be determined from the shaft speed.

By utilizing a set of test parameters listed in Table I, the relationship between shaft speed $(N)$, generator output $\left(P_{\mathrm{g}}\right)$ and load resistance $\left(R_{1}\right)$ can be obtained in Figure 8(a) and 8(b), 

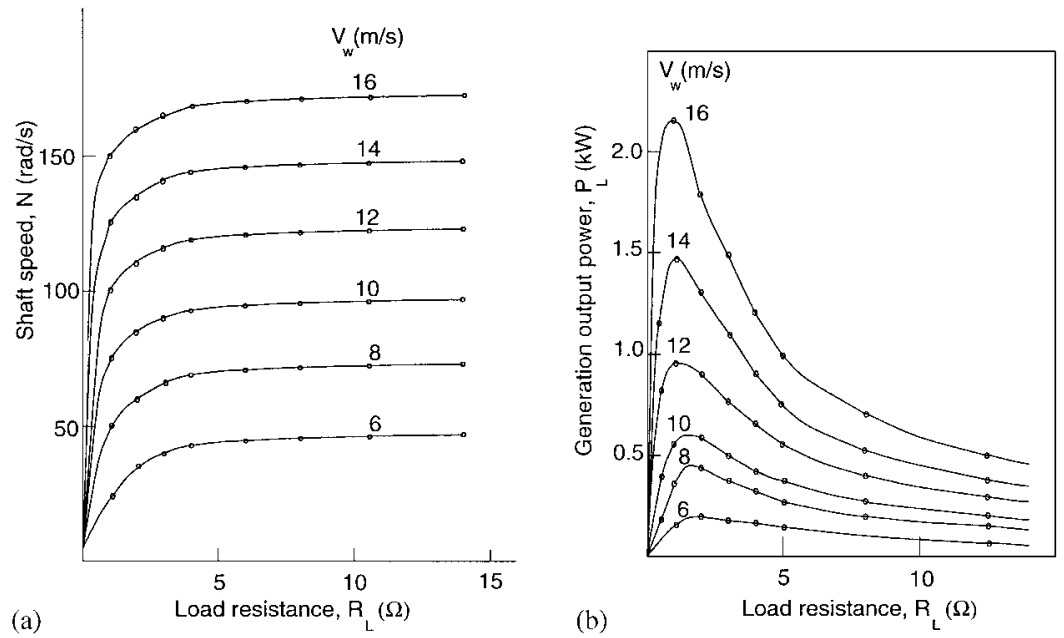

Figure 8. The variation of (a) shaft speed (b) generator output power with load resistance.

respectively. It is seen in Figure $8(\mathrm{~b})$ that the maximum output power occurs at a particular value of $R_{1}$ and that the output power of a wind aero-turbine/generator system depends greatly on the wind speed.

Therefore, due to the vast variations of wind speed, a sufficient energy storage system is needed to supply the load during calm periods. This leads us to the hydrogen storage system.

\section{HYDROGEN STORAGE/CONVERSION SYSTEM}

Hydrogen can be viewed as a clean, storable, and transportable fuel that can be made from abundant resources: sunlight and water. It is a storage medium with infinitely long shelf life. Although hydrogen as a fuel has a low-energy density compared to other storable fuels, there must be justification for its use. This justification must include clean combustion, transportability and storage techniques.

\subsection{Conversion}

Figure 9 shows a schematic of a typical electrolytic hydrogen generation plant. When the load demand is less than the output of the generator in Figure 1, the excess DC power is relayed to the electrolytic cell where it is used to electrolyze the de-ionized water. The electrolytic process of decomposing water into hydrogen and oxygen is the reverse of hydrogen combustion or

$$
2 \mathrm{H}_{2} \mathrm{O} \rightarrow 2 \mathrm{H}_{2}+\mathrm{O}_{2}
$$

The theoretical amount of energy required is the same as the heat of combustion. Ideally, the energy input would be $39.3 \mathrm{kWh} \mathrm{kg}^{-1} \mathrm{H}_{2}$ of which only $33.3 \mathrm{kWh}$ would be used as be electrical and the remainder could be heat. 


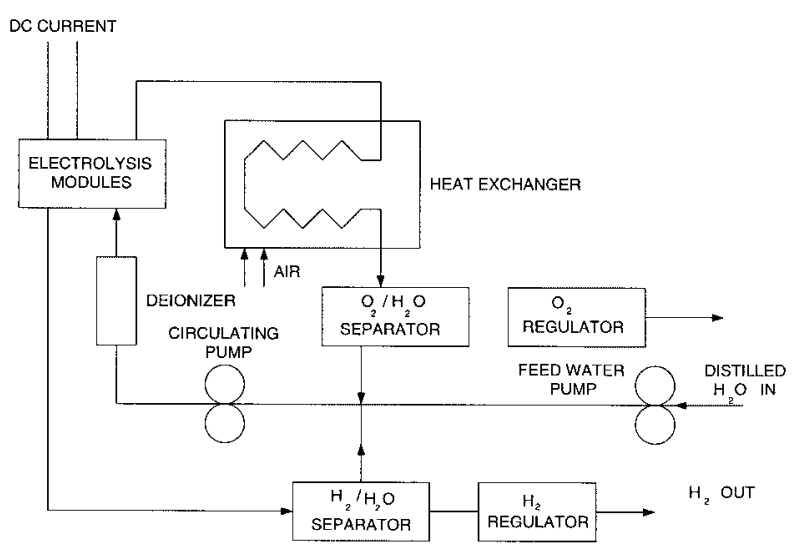

Figure 9. Electrolytic hydrogen generation.

The theoretical decomposition voltage of water corresponding to this minimal electrical energy input is

$$
\begin{aligned}
& 2 \mathrm{H}^{+}+2 \mathrm{e}^{-} \rightarrow \mathrm{H}_{2}, \quad E=0.41 \mathrm{~V} \\
& 2 \mathrm{H}_{2} \mathrm{O} \rightarrow \mathrm{O}_{2}+4 \mathrm{H}^{+}+4 \mathrm{e}^{-}, \quad E=0.82 \mathrm{~V} \\
& \Delta E=1.23 \mathrm{~V}
\end{aligned}
$$

at one atmosphere and $25^{\circ} \mathrm{C}$. Excess voltage above $1.23 \mathrm{~V}$ consists of three principle components; namely, Ohmic resistance of the electrolyte and over voltages at the hydrogen and oxygen electrodes.

Since the efficiency of most electrolyzers is nearly 100 per cent, the overall efficiency of hydrogen production relies heavily on the voltage. The thermal efficiency of electrolysis is the cell potential corresponding to $1.4 \mathrm{~V}$ at $1 \mathrm{~atm}$ with no heat input (thermoneutral) divided by the actual operating voltage

$$
\eta_{\mathrm{elec}}=E_{\mathrm{th}} / E_{\mathrm{op}}
$$

This corresponds to the ratio of the higher heating value of hydrogen produced to the electrical energy input. Or for one pound hydrogen produced,

$$
\eta_{\mathrm{elec}}=0.95
$$

The efficiency and cost of this system can be altered by changing the current input, operating voltage and capital cost. All these factors depend greatly on the current-voltage characteristics of each electrolyzer.

The theoretical cell voltage (thermoneutral) of the electrolysis cell decreases with increasing temperature and increases with increasing pressure. The approximate linear relationship between this voltage and pressure is illustrated in Figure 10 for intermediate temperatures.

Since the thermal efficiency of the cell has been determined to be $\eta_{\mathrm{elec}}=E_{\mathrm{th}} / E_{\mathrm{op}}$, it is obvious that increasing the cell pressure be beneficial. However, temperature should not be decreased for the same reason, because ideally the cell should be operated with as much heat input as 


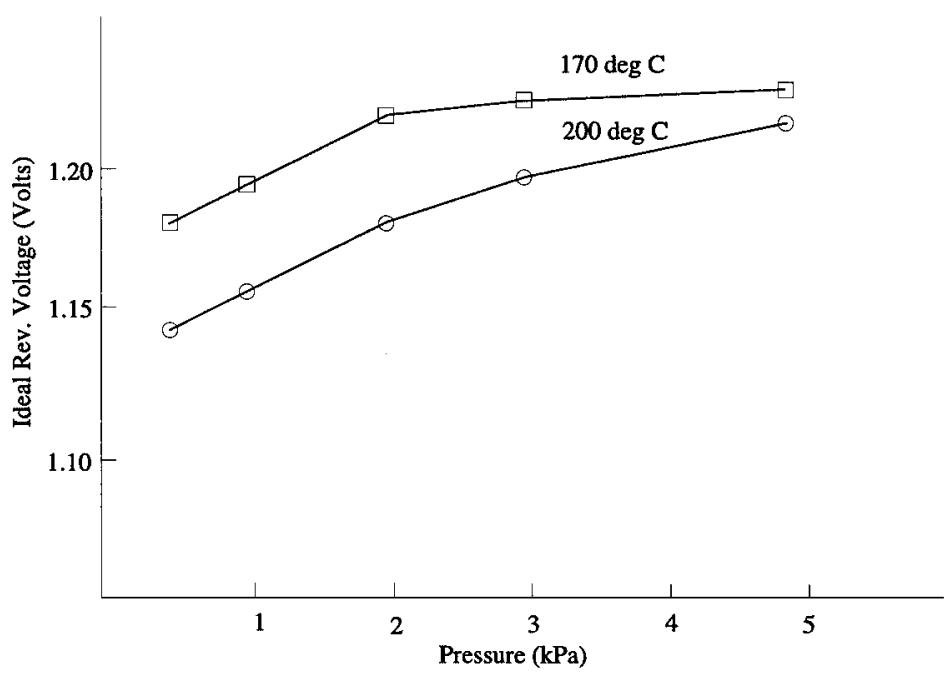

Figure 10. Voltage-pressure relation in reversible electrolysis.

theoretically possible $\left(6 \mathrm{kWh} \mathrm{kg}^{-1} \mathrm{H}_{2}\right)$. Therefore, it is most efficient to operate the cell at intermediate temperatures.

\subsection{Compression/storage}

Hydrogen can be stored as hydrogen compressed gas or liquid. However, when stored as a liquid, hydrogen loses much energy due to the liquefaction process. Therefore, storage of hydrogen as compressed gas offers the best option. The simulation of a single-stage reciprocating compressor and the determination of the corresponding compressor power requirement are omitted here.

As an illustrative example, consider a case in which a windmill operates under a wind speed of $14 \mathrm{~m} \mathrm{~s}^{-1}$. From Figure 6, the maximum generator power, $P_{\mathrm{g}}$ of around $2 \mathrm{~kW}$ is achieved at a load coefficient, $k_{\tau_{1}}$ of 0.2 . The entire $2 \mathrm{~kW}$ may be expended in electrical output. In case only part of it is used in electrical output, the balance can be stored in the form of electrolysis as shown in the lower half of Figure 1.

\section{CONCLUDING REMARKS}

The wind energy-hydrogen storage hybrid power generation system has been theoretically treated. The merits of the system include the use of renewable energy source without polluting the environment. Once the hydrogen is stored in an appropriate high-pressure vessel, it can be used in a combustion engine, fuel cell or burned in a water cooled burner. When hydrogen and oxygen are burned in an aphedoid burner, a very high-quality steam is produced. This steam is ideal to use for space heating, or to drive a turbine to produce electrical output. It can also be combined with organic materials to produce synthetic fuels. The system in Figure 1 also works well with a solar collector. Since the sun and wind power usually compliment each other, this could prove 
to be a good combination. In addition, most importantly the solar energy-hydrogen storage power generation system also produces no harmful waste and depletes no resources.

\section{ACKNOWLEDGEMENTS}

The authors wish to thank Ms W. Junker for her contribution in the initial stage of this research. The second author is indebted to financial supports from TUBITAK and NATO.

\section{APPENDIX: NOMENCLATURE}

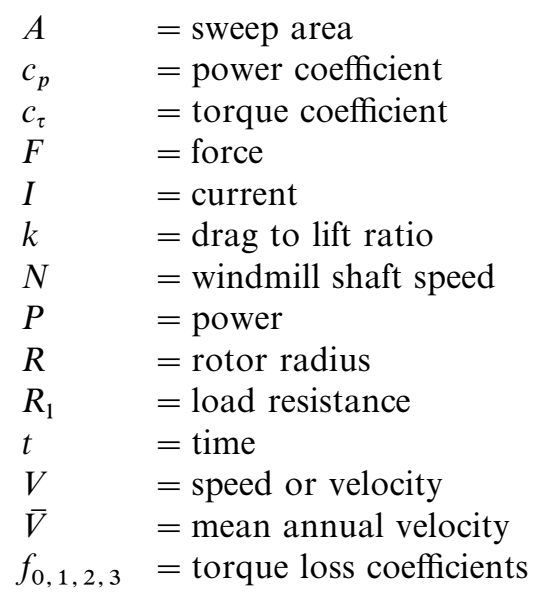

Greek symbols

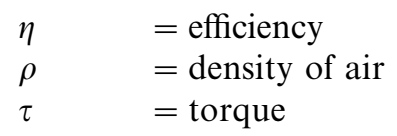

Subscripts

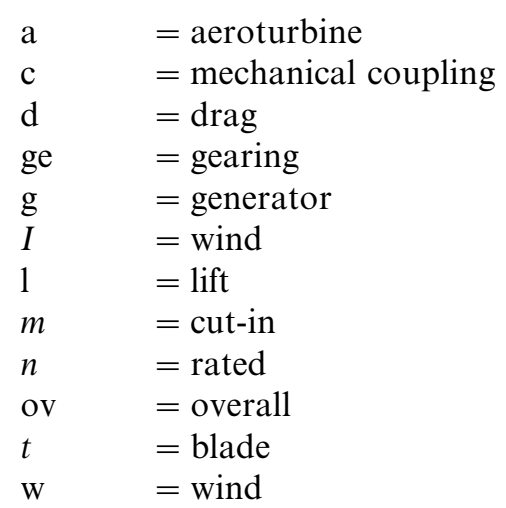




\section{REFERENCES}

Andrews JW. 1976. Energy-storage requirements reduced in coupled wind-solar generating systems. Solar Energy 18(1):73-74.

Ashari M, Nayar CV. 1999. An optimum dispatch strategy using set points for a photovoltaic (PV)-diesel-battery hybrid power system. Solar Energy 66(1):1-9.

Ashenayi K, Ramakumar R. 1990. IRES-a program to design integrated renewable energy systems. Energy 15(12):1143-1152.

Barley CD, Winn CB. 1996. Optimal dispatch strategy in remote hybrid power systems. Solar Energy 58(4-6):165-179.

Bonanno F, Consoli A, Raciti A, Morgana B, Nocera U. 1999. Transient analysis of integrated diesel-wind-photovoltaic generation system. IEEE Transactions on Energy Conversion 14(2):232-238.

Borowy BS, Salameh ZM. 1994. Optimum photovoltaic array size for a hybrid wind PV system. IEEE Transactions on Energy Conversion 9(3):482-488.

Borowy BS, Salameh ZM. 1996. Methodology for optimally sizing the combination of a battery bank and PV array in a Wind/PV hybrid system. IEEE Transactions on Energy Conversion 11(2):367-373.

Kellog WD, Nehrir MH, Venkataramanan G, Gerez V. 1994. Generation unit sizing and cost analysis for stand-alone wind, photovoltaic, and hybrid wind/PV systems. IEEE Transactions on Energy Conversion 13(1):70-75.

Kellog WD, Nehrir MH, Venkataramanan G, Gerez V. 1997. Optimal sizing for a hybrid wind photovoltaic generating system. Electric Power Systems Research 39(1):35-38.

Markvart T. 1996. Sizing of hybrid photovoltaic-wind energy systems. Solar Energy 57(4):277-281.

Muselli M, Notton G, Louche A. 1999. Design of hybrid-photovoltaic power generator, with optimization of energy management. Solar Energy 65(3):143-157.

Peterson AJ, Perez R, Bailey B, Elsholz K. 1999. Operational experience of a residential photovoltaic hybrid system. Solar Energy 65(4):227-235.

Ramakumar R. 1976. An assessment of hydrogen as a means to store solar energy. Proceedings of Sharing The Sun! Solar Technology in the Seventies Conference, Winnepeg, Canada, The American Section of the International Solar Energy Society, vol. 8, pp. 163-175.

Ramakumar R, Allison HJ, Hughes WL. 1975. Solar energy conversion and storage systems for the future. IEEE Transactions on Power Apparatus and Systems PAS-94(6):1926-1934.

Ramakumar R. 1983. Storage options for harnessing wind energy. Mechanical Enginnering 74-83.

Ramakumar R, Abouzahr I, Ashenayi K. 1992. A knowledge-based approach to the design of integrated renewable energy-systems. Kellog WD, Nehrir MH, Venkataramanan G, Gerez V 1994 (4):648-659.

Ramakumar R, Abouzahr I, Krishnan K, Ashenayi K. 1995. Design scenarios for integrated renewable energy systems. IEEE Transactions on Energy Conversion 10(4):736-746.

Seeling-Hochmuth GC. 1997. A combined optimisation concept for the design and operation strategy of hybrid-PV energy systems. Solar Energy 61(2):77-87.

Swet CJ. 1981. Energy storage for solar applications. In Solar Energy Handbook, Kreider JF, Kreith F (eds.), chap. 6. McGraw-Hill: New York, pp. 1-35.

Yokoyama R, Ito K, Yuasa Y. 1994. Multiobjective optimal unit sizing of hybrid power generation systems utilizing photovoltaic and wind energy. Journal of Solar Energy Engineering 116(4):167-174.

Yokoyama R, Ito K, Sakashita M, Matsumoto Y, Yuasa Y. 1997. Multiobjective optimal unit sizing of grid-connected photovoltaic system in consideration of its probabilistic characteristics. Journal of Solar Energy Engineering 119(2): 134-140. 